\title{
A systematic review and meta-analysis of elastic stockings for prevention of thrombosis after orthopedic surgery
}

\author{
Bo Tan ${ }^{1,2 \#}$, Chengwei Xiao ${ }^{1,2 \#}$, Ming Cheng ${ }^{3}$, Zongdong Zhu ${ }^{1,2}$, Feng Liao ${ }^{1,2}$, Bing Lu ${ }^{1,2}$, Jiabin Yuan ${ }^{1,2}$, \\ Dan Wei ${ }^{1,2}$, Bo Lv ${ }^{1,2}$, Jianxin Zhu ${ }^{1,2}$, Chongxin Huang ${ }^{1,2}$, Xiaoming Tang ${ }^{1,2}$, Jiang Hu ${ }^{1,2}$ \\ ${ }^{1}$ Department of Orthopedics, Sichuan Academy of Medical Sciences, Sichuan Provincial People's Hospital, Chengdu, China; ${ }^{2}$ University of \\ Electronic Science and Technology of China, Chengdu, China; ${ }^{3}$ Department of Rehabilitation, Jinniu District People's Hospital of Chengdu, \\ Chengdu, China \\ Contributions: (I) Conception and design: All authors; (II) Administrative support: All authors; (III) Provision of study materials or patients: All \\ authors; (IV) Collection and assembly of data: All authors; (V) Data analysis and interpretation: All authors; (VI) Manuscript writing: All authors; (VII) \\ Final approval of manuscript: All authors. \\ \#These authors contributed equally to this work as co-first authors. \\ Correspondence to: Jiang Hu; Xiaoming Tang. Department of Orthopedics, Sichuan Academy of Medical Sciences, Sichuan Provincial People's \\ Hospital, Chengdu 610072, China; Affiliated Hospital of University of Electronic Science and Technology of China, Chengdu, China. Email: \\ 470129139@qq.com; 11000338@qq.com.
}

Background To investigate the preventive effect of elastic stockings on deep vein thrombosis (DVT) after orthopedic surgery by literature search and meta-analysis.

Methods: PubMed, Embase and Cochrane were selected as the search database platforms to search the literature of randomized controlled trials related to elastic stockings and DVT published from 2008 to date. Revman 5.3.5 software was used for statistical analysis of the data to obtain forest and funnel plots.

Results: In this study, 90 studies were initially screened and 7 were finally included, covering a total of 3,116 patients. Meta-analysis showed that the 7 studies had statistical heterogeneity $\left(\mathrm{I}^{2}=32 \%, \mathrm{P}=0.18\right)$, so a random effect model was used. The obtained statistic was [odds ratio $(\mathrm{OR})=0.59,95 \%$ confidence interval (CI): $(0.34,1.03)]$, the statistical effect size was $Z=1.84, P=0.07$, and the difference was not statistically significant, so a stepwise sensitivity analysis was performed by the exclusion method. One study was excluded, and the remaining 6 showed homogeneity $\left(\mathrm{I}^{2}=0 \%, \mathrm{P}=0.46\right)$. They were analyzed by subgroup according to the type of operation: ankle surgery or hip and knee arthroplasty. The internal literatures of each subgroup were homogeneous: ankle surgery subgroup $\left(\mathrm{I}^{2}=0 \%, \mathrm{P}=0.43\right)$, hip and knee arthroplasty subgroup $\left(\mathrm{I}^{2}=0 \%\right.$, $\mathrm{P}=0.88$ ). Therefore, fixed effect mode analysis was used, and the effect size of elastic stockings after ankle surgery was $Z=3.65, P=0.0003$, while the effect size of elastic stockings in the hip and knee arthroplasty subgroup was $\mathrm{Z}=1.23, \mathrm{P}=0.22$.

Discussion: Elastic stockings had an obvious preventive effect on DVT in patients undergoing ankle surgery, but not in patients undergoing lumbar, knee or spinal surgery. It is necessary to combine anticoagulant drugs and other physical therapies to prevent DVT.

Keywords! Deep venous thrombosis (DVT); elastic stockings; meta-analysis; orthopedics

Submitted Jul 27, 2021. Accepted for publication Sep 09, 2021.

doi: 10.21037/apm-21-2231

View this article at: https://dx.doi.org/10.21037/apm-21-2231 


\section{Introduction}

Deep venous thrombosis (DVT) occurs when the blood flow rate slows, or the blood becomes hypercoagulable, which makes the venous blood clot in the blood vessels and can stimulate post-thrombotic syndromes (PTS) such as tissue edema, ulcers, and varicose veins (1). Anesthesia of the orthopedic surgery can slow down the venous flow rate, formating a hypercoagulable state of blood, and after surgery the patients need limb immobilization for recovering, which is also an important cause of postoperative DVT $(2,3)$. The incidence of DVT after orthopedic surgery has been reported to be between $1 \%$ and $25 \%$ (4). Therefore, prevention of postoperative thrombosis is very important, the use of anticoagulant drugs can prevent the formation of new thrombus and dredge the vein that has formed thrombus, in addition, some physical therapies can help to inhibit the growth of thrombus, such as leg elevation, intermittent compression inflation, plantar venous pump, and compression elastic stockings (5). Medical elastic stockings are used to contract the muscles with progressive pressure and squeeze venous blood back to the heart to prevent venous congestion and thus DVT (6). However, the results of such studies vary and the preventive effect of elastic stockings on thrombosis still remains unclear. Thus in the present study we included the latest studies in recent years for a meta-analysis to further clarify the preventive effect of elastic stockings. We present the following article in accordance with the PRISMA reporting checklist (available at https://dx.doi.org/10.21037/apm-21-2231).

\section{Methods}

\section{Search strategy}

PubMed, Embase and Cochrane were selected as the search platforms, using the keywords "stockings" AND "deep vein thrombosis" or "compression stockings" AND "DVT", or "Elastic stockings" AND "DVT" as the search criteria. The publication time and study type were limited to randomized control trials (RCTs) published from 2008 to date.

\section{Inclusion and exclusion criteria}

\section{Inclusion criteria}

(I) Study type: RCT of interventional nature, single- or multi-center study. (II) Study subjects were all patients undergoing orthopedic surgery (ankle surgery, hip arthroplasty, knee arthroplasty, spinal surgery, etc.). The patients were aged over 18 years, and did not have lower extremity DVT before surgery. (III) The study group must contain the elastic stockings and control groups. All patients took the same basic prevention method: anticoagulant drugs were given to high-risk patients with DVT, and asymptomatic patients did not need drug treatment, but ultrasound was given every 1 week. On this basis, the patients in the experimental group were given elastic socks physical therapy, whereas the control group was limited to a placebo medical cylindrical bandage or no preventive measures. (IV) The study clearly described the DVT diagnostic method (biphasic ultrasound), diagnostic criteria and DVT index data.

\section{Exclusion criteria}

(I) Non-randomized, non-concurrent controlled study, observational case-control study, cross-sectional study, review, guideline, investigation, case analysis, systematic review. (II) The study did not specify the orthopedic surgery, or the study subjects were mixed with the study including gynecological, cardiac surgery and other surgical patients. (III) The study subjects had been diagnosed as DVT patients before surgery. (IV) The study used elastic stockings as a treatment but not as a preventive measure.

\section{Risk of bias assessment}

We evaluated the risk of bias in the studies from six aspects according to the criteria in the Cochrane Handbook for Systematic Reviews of Interventions (7): the generation of random sequences, classification concealment, blind method, whether outcome assessment was incomplete, selective reporting, and other biases.

\section{Literature screening}

Two researchers searched the databases, combined the search results, read the abstracts of each study as the primary screening, read the full text of the study after primary screening, continued screening according to the inclusion and exclusion criteria, and evaluated the quality of the studies for inclusion in the analysis, as shown in Figure 1.

\section{Data collection}

The researchers read the full text of each of the included articles, and extracted the following information: authors, year of publication, the number of interventions, sex ratio, 


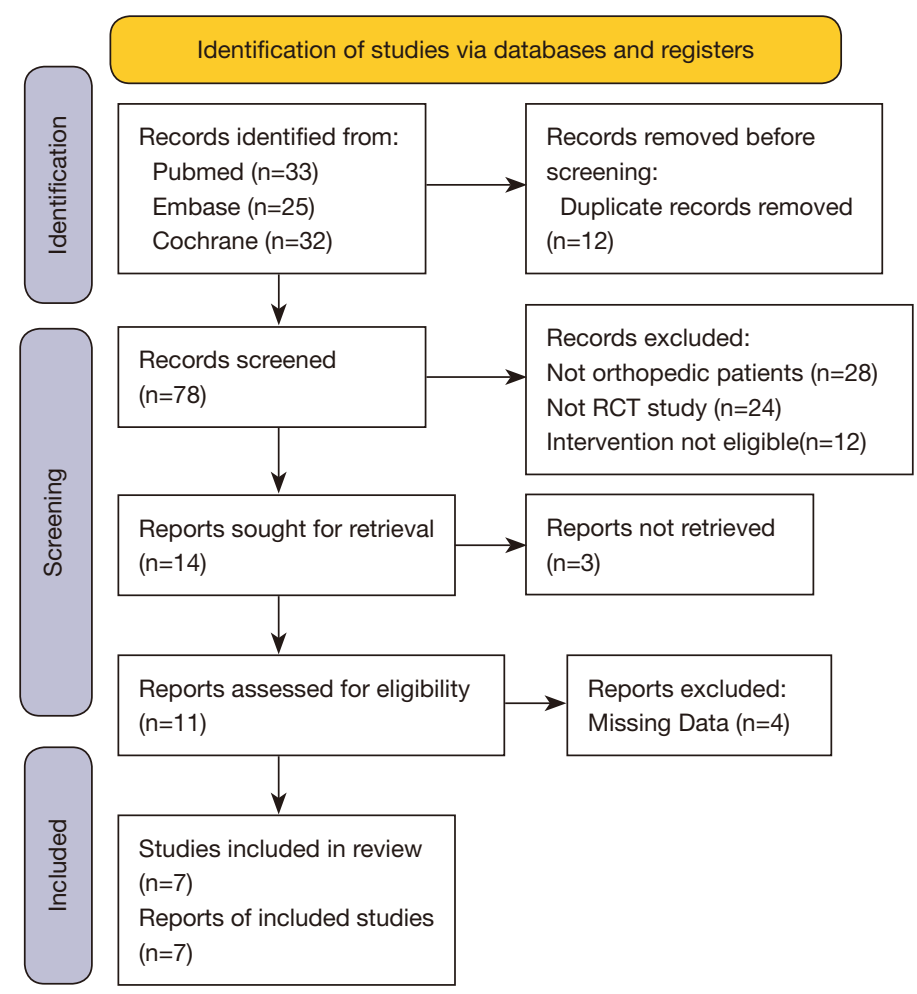

\begin{abstract}
Consider, if feasible to do so, reporting the number of records identified from each database or register searched (rather than the total number across all databases/registers).

If automation tools were used, indicate how many records were excluded by a human and how many were excluded by automation tools.

From: Page MJ, McKenzie JE, Bossuyt PM, Boutron I, Hoffmann TC, Mulrow CD, et al. The PRISMA 2020 statement: an updated guideline for reporting systematic reviews. BMJ 2021;372:n71. doi: 10.1136/bmj.n71

For more information, visit: http://www.prisma-statement.org/
\end{abstract}

Figure 1 Flow chart of literature search and screening. RCT, randomized control trial.

age, surgical procedure, intervention methods for study and control groups, and the incidence of DVT. The data were organized into tables for further analysis.

\section{Statistical analysis}

We used Revman 5.3.5 software released by the Cochrane Collaboration for comprehensive analysis, the statistical method was Mantel-Haenszel (M-H) and the odds ratio $(\mathrm{OR})$ and $95 \%$ confidence interval $(\mathrm{CI})$ were used to report the incidence of DVT in the two groups of intervention methods, with $\mathrm{P}<0.05$ considered statistically significant. The software created forest plots to display the results. All studies with DVT incidence were included in the study and the index expressed by \% in all studies was converted into actual numbers of cases. The heterogeneity of the studies was analyzed by $\mathrm{I}^{2}$ analysis and $\mathrm{Q}$ validation, and $\mathrm{I}^{2}>25 \%$ or $\mathrm{P}<0.1$ indicated heterogeneity of results. If heterogeneity among the studies was suggested, sensitivity analysis was performed using literature analysis and a case-by-case elimination method, and a funnel plot was used to represent publication bias.

\section{Results}

\section{Literature screening results}

We initially screened 90 studies and based on our inclusion and exclusion criteria and literature quality evaluation, 7 were finally included, covering a total of 3,116 patients (Table 1). 
Table 1 Baseline characteristics of the included studies of DVT

\begin{tabular}{|c|c|c|c|c|c|c|c|c|}
\hline Authors & Year & $\begin{array}{l}\text { Number } \\
(\mathrm{T} / \mathrm{C})\end{array}$ & Male $(\mathrm{T} / \mathrm{C})$ & $\begin{array}{c}\text { Mean age } \\
\text { (years) }(\mathrm{T} / \mathrm{C})\end{array}$ & Surgery & $\begin{array}{l}\text { Intervention group } \\
\text { mode }\end{array}$ & Control group mode & $\begin{array}{l}\text { DVT events } \\
\qquad(\mathrm{T} / \mathrm{C})\end{array}$ \\
\hline $\begin{array}{l}\text { Sultan } \\
\text { et al. (8) }\end{array}$ & 2014 & $44 / 46$ & $25 / 29$ & $46.4 / 47.0$ & Ankle surgery & $\begin{array}{l}\text { Compression } \\
\text { stockings }\end{array}$ & $\begin{array}{l}\text { TubiGrip Medical } \\
\text { Cannulated Bandage }\end{array}$ & $5 / 10$ \\
\hline $\begin{array}{l}\text { Winge } \\
\text { et al. (9) }\end{array}$ & 2018 & $82 / 71$ & $28 / 29$ & $57.0 / 61.0$ & Ankle surgery & $\begin{array}{l}\text { Compression } \\
\text { stockings }\end{array}$ & $\begin{array}{l}\text { TubiGrip Medical } \\
\text { Cannulated Bandage }\end{array}$ & $14 / 31$ \\
\hline $\begin{array}{l}\text { Kim } \\
\text { et al. (11) }\end{array}$ & 2015 & $40 / 50$ & NA & NA & $\begin{array}{l}\text { Hip/knee } \\
\text { arthroplasty }\end{array}$ & $\begin{array}{l}\text { Graded compression } \\
\text { stockings }\end{array}$ & No precautions & $2 / 3$ \\
\hline $\begin{array}{l}\text { Maki } \\
\text { et al. (12) }\end{array}$ & 2021 & $595 / 164$ & $234 / 76$ & $56.0 / 58.0$ & $\begin{array}{l}\text { Hip/knee } \\
\text { arthroplasty }\end{array}$ & $\begin{array}{l}\text { Compression } \\
\text { stockings }\end{array}$ & No precautions & $2 / 0$ \\
\hline
\end{tabular}

DVT, deep vein thrombosis; T, intervention group; C, control group; NA, not available.

Table 2 Bias assessment based on Cochrane systematic review criteria for randomized interventions

\begin{tabular}{|c|c|c|c|c|c|c|}
\hline Study & $\begin{array}{l}\text { Generation of random } \\
\text { sequence }\end{array}$ & $\begin{array}{l}\text { Classification } \\
\text { hiding }\end{array}$ & Blind method & $\begin{array}{l}\text { Inadequate outcome } \\
\text { assessment }\end{array}$ & $\begin{array}{l}\text { Optional } \\
\text { reporting }\end{array}$ & Other bias \\
\hline Sultan et al. (8) & Yes & Yes & Yes & Yes & Unclear & Unclear \\
\hline Chin et al. (10) & Yes & Yes & Unclear & Yes & Yes & Unclear \\
\hline Majeed et al. (13) & Yes & Unclear & Yes & Yes & Yes & Unclear \\
\hline Takahashi et al. (14) & Yes & Yes & Yes & Yes & Yes & Yes \\
\hline
\end{tabular}

\section{Risk of bias assessment}

The bias of the 7 studies was assessed according to Cochrane Randomized Intervention Evaluation System (Table 2).

\section{Meta-analysis results}

\section{Statistical analysis}

Meta-analysis showed that the 7 studies had statistical heterogeneity $\left(\mathrm{I}^{2}=32 \%, \mathrm{P}=0.18\right)$, so a random effect model was used, and the obtained statistics were $[\mathrm{OR}=0.59,95 \%$ CI: $(0.34,1.03)]$. The statistical effect value was $Z=1.84$,
$\mathrm{P}=0.07$, and the difference was not statistically significant, as shown in Figure 2. The risk of literature bias may bias the results.

\section{Sensitivity analysis}

Due to heterogeneity in the 7 articles, the study by Takahashi et al. (14), which described spinal surgery, was excluded by the case-by-case exclusion method, and the remaining 6 studies showed homogeneity $\left(\mathrm{I}^{2}=0 \%, \mathrm{P}=0.46\right)$. These studies were analyzed by subgroup according to the type of operation: ankle surgery or hip and knee arthroplasty. The internal validity of each subgroup showed homogeneous: ankle surgery subgroup $\left(\mathrm{I}^{2}=0 \%, \mathrm{P}=0.43\right)$, 


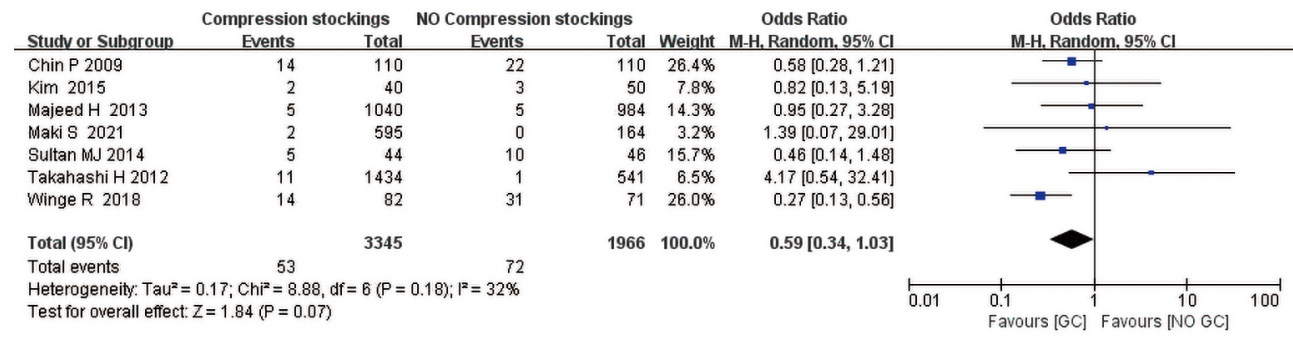

Figure 2 Forest plot of use of elastic stockings for the prevention of DVT after orthopedic surgery. CI, confidence interval; DVT, deep vein thrombosis.

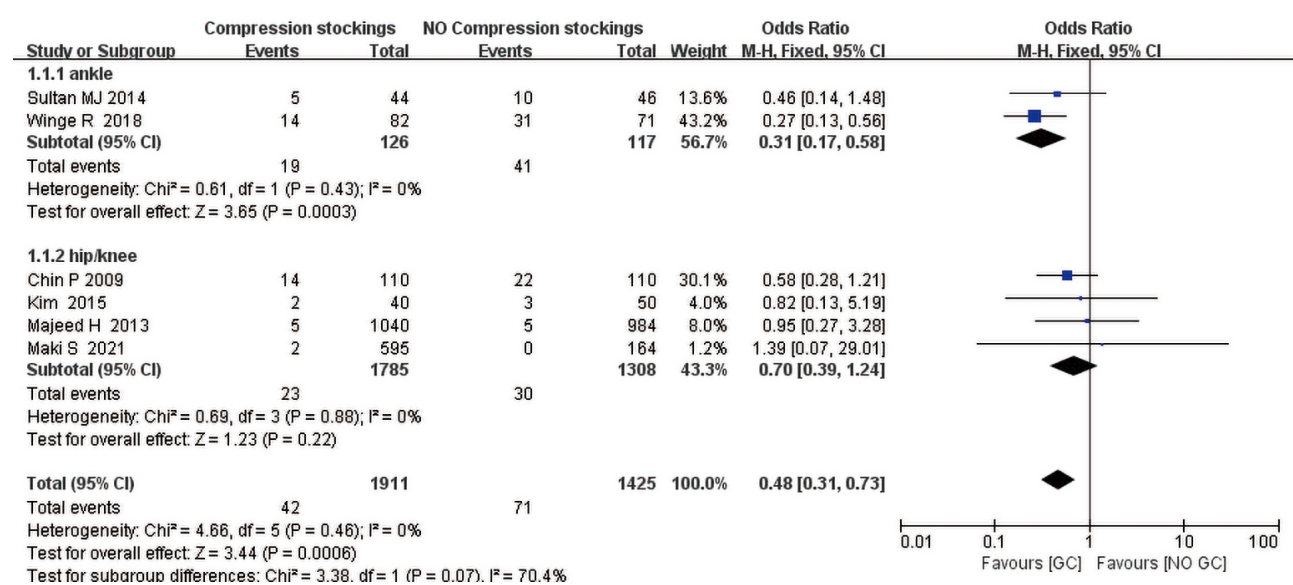

Figure 3 Forest plot of subgroups of elastic stocking use for the prevention of DVT after orthopedic surgery. CI, confidence interval; DVT, deep vein thrombosis.

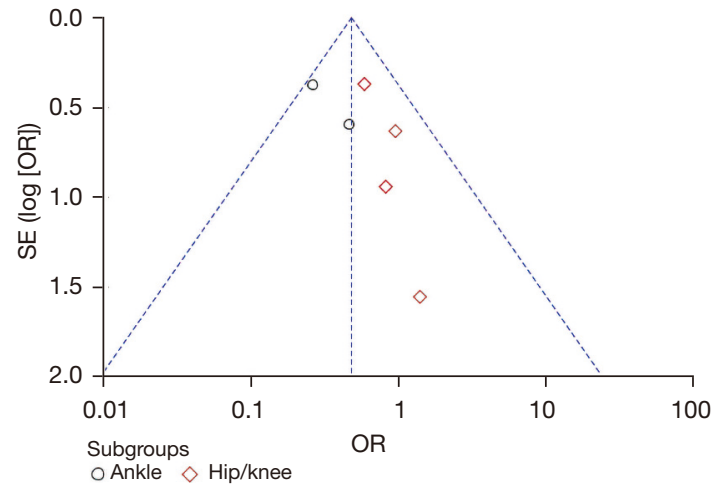

Figure 4 Funnel plot of use of elastic stockings for prevention of DVT after orthopedic surgery. DVT, deep vein thrombosis.

hip and knee arthroplasty subgroup $\left(\mathrm{I}^{2}=0 \%, \mathrm{P}=0.88\right)$. Using fixed effect mode analysis, the effect size of elastic stockings after ankle surgery was $Z=3.65, P=0.0003$, suggesting that the use of elastic stockings can prevent the occurrence of
DVT, whereas the effect size of elastic stockings in the hip and knee arthroplasty subgroup was $\mathrm{Z}=1.23, \mathrm{P}=0.22$, suggesting no significant effect in preventing the occurrence of DVT (Figure 3).

\section{Analysis of publication bias}

The funnel plot showed that the two subgroups were unevenly distributed, suggesting the presence of publication bias (Figure 4).

\section{Discussion}

Lower extremity DVT is an abnormal blood coagulation state that can cause vascular intimal lesions, causing varying degrees of PTS, and even the risk of pulmonary embolism (PE) (15). Medical elastic stockings are a physical therapy measure that produce a stepped decrease in pressure from the ankle, which reduces blood viscosity, promotes blood return, increases flow rate, reduces blood stasis, and protects 
the vascular endothelium, thereby achieving the effect of preventing DVT (16). However, its application effect is still under discussion; some studies $(8,10-12)$ have shown an obvious preventive effect on DVT, while some studies $(9,13,14)$ believe the preventive effect is not significantly different from that of conventional measures. In this study, a total of 3,116 orthopedic surgery patients in 7 articles were screened for a meta-analysis, and the study results showed that in the random effect mode, the OR of DVT was $[0.59,95 \%$ CI: $(0.34,1.03)]$ when elastic stockings were used versus no elastic stockings, but the statistic value was $Z=1.84, P=0.09$, suggesting that the difference was not statistically significant; that is, elastic stockings had no significant preventive effect on DVT. This is different from meta-analyses performed by Sachdeva et al. (17) and Hajibandeh et al. (18), and may be due to the fact that we focused on patients after orthopedic surgery, whereas the subjects of the other meta-analysis were patients with different surgeries. Our result suggests that for patients undergoing orthopedic surgery, it is not enough to use elastic stockings alone for DVT prevention, and it needs to be performed in combination with other methods such as anticoagulant drugs, pneumatic compression, etc., in order to achieve better results.

In this study, the 7 articles showed heterogeneity $\left(\mathrm{I}^{2}=32 \%, \mathrm{P}=0.18\right)$, so the case-by-case exclusion method was used for the sensitivity analysis. The results showed that after removing the study (14) whose subjects were patients undergoing spinal surgery, the remaining 6 showed homogeneity $\left(\mathrm{I}^{2}=0 \%, \mathrm{P}=0.46\right)$, so they were analyzed according to the surgical procedure. The results showed homogeneity among the internal literatures, while the heterogeneity between the subgroups was higher $\left(\mathrm{I}^{2}=70.4 \%\right)$, suggesting that the benefit of using elastic stockings in patients undergoing ankle surgery was different from that in patients undergoing hip and knee surgery. The statistical value showed that the effect size of using elastic stockings after ankle surgery was $Z=3.65, P=0.0003$, suggesting that the use of elastic stockings can effectively prevent the occurrence of DVT; while the effect size of using elastic stockings after hip and knee arthroplasty was $Z=1.23$, $\mathrm{P}=0.22$, suggesting no significant effect on preventing the occurrence of DVT. A study by Ayhan et al. (19) showed that there was a difference in patient comfort between elastic stockings for the knee and those for the hip, which may affect patient compliance. The types of elastic stockings used after different orthopedic surgeries differ, so their preventive effect on DVT may also differ. In addition, for the surgeries with a wide range of effects, the possibility of postoperative DVT in patients is higher, and the preventive effect of elastic stockings is limited, so should be combined with other anticoagulant methods.

In this study, the publication bias analysis was performed for the 6 studies remaining after excluding the study by Takahashi et al. (14). Our analysis found significant asymmetry on both sides of the funnel plot, suggesting there was a risk of publication bias. One possible reason was that people overestimated the effect of elastic stockings. In addition, there are various types of elastic stockings that produce different pressures. One study (20) showed that graded elastic stockings had the best preventive effect when the pressure was $18 \mathrm{mmHg}$ at the ankle, $14 \mathrm{mmHg}$ at the lower leg and $8 \mathrm{mmHg}$ at the knee. We did not distinguish the specific types of elastic stockings used in the different studies. In addition, we did not record the intervention duration of elastic stockings in the studies, which varied from 2 weeks to 3 months. In a study conducted by Health Quality Ontario (21), wearing a compress stocking may be an effective way of preventing chronic venous and it's costeffective for the long run, and it could help to reduce the recurrence of DVT by half.

All the studies did not report side effects of compress stockings, but as Robertson BF (22) reported, for those who are at greater risk of skin damage, the application of compress stockings need careful assessment and close monitoring.

One study (23) showed that for patients with moderate or high risk of DVT before elective surgery, pharmacological thromboprophylaxis alone was not inferior to the combination of pharmacological thromboprophylaxis and compression stockings, which means anticoagulant drugs still should be the dominant way to preventing DVT.

\section{Conclusions}

In this meta-analysis of the preventive effect of elastic stockings on DVT after orthopedic surgery, a total of 3,116 patients in 7 studies were included. The results showed that elastic stockings had a significant preventive effect on DVT in patients undergoing ankle surgery, but not in patients undergoing lumbar, knee or spinal surgery. It is necessary to combine anticoagulant drugs and other physical therapy methods to jointly prevent DVT.

\section{Acknowledgments}

Funding: None. 


\section{Footnote}

Reporting Checklist: The authors have completed the PRISMA reporting checklist. Available at https://dx.doi. org/10.21037/apm-21-2231

Conflicts of Interest: All authors have completed the ICMJE uniform disclosure form (available at https://dx.doi. org/10.21037/apm-21-2231). The authors have no conflicts of interest to declare.

Ethical Statement: The authors are accountable for all aspects of the work in ensuring that questions related to the accuracy or integrity of any part of the work are appropriately investigated and resolved.

Open Access Statement: This is an Open Access article distributed in accordance with the Creative Commons Attribution-NonCommercial-NoDerivs 4.0 International License (CC BY-NC-ND 4.0), which permits the noncommercial replication and distribution of the article with the strict proviso that no changes or edits are made and the original work is properly cited (including links to both the formal publication through the relevant DOI and the license). See: https://creativecommons.org/licenses/by-nc-nd/4.0/.

\section{References}

1. Raskob GE, Silverstein R, Bratzler DW, et al. Surveillance for deep vein thrombosis and pulmonary embolism: recommendations from a national workshop. Am J Prev Med 2010;38:S502-9.

2. Georgopoulos G, Hotchkiss MS, McNair B, et al. Incidence of Deep Vein Thrombosis and Pulmonary Embolism in the Elective Pediatric Orthopaedic Patient. J Pediatr Orthop 2016;36:101-9.

3. Buckner TW, Leavitt AD, Ragni M, et al. Prospective, multicenter study of postoperative deep-vein thrombosis in patients with haemophilia undergoing major orthopaedic surgery. Thromb Haemost 2016;116:42-9.

4. Abdel-Hamid H, Miles J, Carrington RW, et al. Combined Vascular and Orthopaedic Approach for a Pseudotumor Causing Deep Vein Thrombosis after Metal-onMetal Hip Resurfacing Arthroplasty. Case Rep Orthop 2015;2015:926263.

5. Mazzone C, Chiodo GF, Sandercock P, et al. Physical methods for preventing deep vein thrombosis in stroke. Cochrane Database Syst Rev 2004;(4):CD001922.
6. Berntsen CF, Kristiansen A, Akl EA, et al. Compression Stockings for Preventing the Postthrombotic Syndrome in Patients with Deep Vein Thrombosis. Am J Med 2016;129:447.e1-447.e20.

7. The Cochrane Collaboration. Cochrane Handbook for Systematic Reviews of Interventions. Available online: http://www.cochrane.org

8. Sultan MJ, Zhing T, Morris J, et al. Compression stockings in the management of fractures of the ankle: a randomised controlled trial. Bone Joint J 2014;96-B:1062-9.

9. Winge R, Ryge C, Bayer L, et al. Wound complications after ankle surgery. Does compression treatment work? A randomized, controlled trial. Eur J Trauma Emerg Surg 2018;44:947-56.

10. Chin PL, Amin MS, Yang KY, et al. Thromboembolic prophylaxis for total knee arthroplasty in Asian patients: a randomised controlled trial. J Orthop Surg (Hong Kong) 2009;17:1-5.

11. Kim H, Cho O, Kim J, et al. Prevention Effects of Graduated Compression Stockings and Intermittent Pneumatic Compression on Deep Vein Thrombosis in SICU Patients: Pilot Study. Journal of Korean Academy of Fundamentals of Nursing 2015;22:249-57.

12. Maki S, Baskaradas A, Smith J. Thromboprophylaxis In Elective Arthroplasty Patients: Assessing DVT Rates. Br J Surg 2021;108:znab134-248.

13. Majeed H. Value of Graduated Compression Stockings in Prevention of Venous Majeed H1* and Szypryt EP2Thromboembolism after Total Hip and Knee Arthroplasty. Journal of General Practice 2013;01:2.

14. Takahashi H, Yokoyama Y, Iida $Y$, et al. Incidence of venous thromboembolism after spine surgery. J Orthop Sci 2012;17:114-7.

15. Hui AC, Heras-Palou C, Dunn I, et al. Graded compression stockings for prevention of deep-vein thrombosis after hip and knee replacement. J Bone Joint Surg Br 1996;78:550-4.

16. Kahn SR, Shapiro S, Wells PS, et al. Compression stockings to prevent post-thrombotic syndrome: a randomised placebo-controlled trial. Lancet 2014;383:880-8.

17. Sachdeva A, Dalton M, Amaragiri SV, et al. Graduated compression stockings for prevention of deep vein thrombosis. Cochrane Database Syst Rev 2014;(12):CD001484.

18. Hajibandeh S, Hajibandeh S, Antoniou GA, et al. Neuromuscular electrical stimulation for the prevention of venous thromboembolism. Cochrane Database Syst Rev 
2017;11:CD011764.

19. Ayhan $\mathrm{H}$, Iyigun $\mathrm{E}$, Ince $\mathrm{S}$, et al. A randomised clinical trial comparing the patient comfort and efficacy of three different graduated compression stockings in the prevention of postoperative deep vein thrombosis. J Clin Nurs 2015;24:2247-57.

20. Sigel B, Edelstein AL, Savitch L, et al. Type of compression for reducing venous stasis. A study of lower extremities during inactive recumbency. Arch Surg 1975;110:171-5.

21. Health Quality Ontario . Compression Stockings for the Prevention of Venous Leg Ulcer Recurrence: A Health

Cite this article as: Tan B, Xiao C, Cheng $M$, Zhu Z, Liao F, Lu B, Yuan J, Wei D, Lv B, Zhu J, Huang C, Tang X, Hu J. A systematic review and meta-analysis of elastic stockings for prevention of thrombosis after orthopedic surgery. Ann Palliat Med 2021;10(10):10467-10474. doi: 10.21037/apm-21-2231
Technology Assessment. Ont Health Technol Assess Ser 2019;19:1-86.

22. Robertson BF, Thomson CH, Siddiqui H. Side effects of compression stockings: a case report. Br J Gen Pract 2014;64:316-7.

23. Shalhoub J, Lawton R, Hudson J, et al. Graduated compression stockings as adjuvant to pharmacothromboprophylaxis in elective surgical patients (GAPS study): randomised controlled trial. BMJ 2020;369:m1309.

(English Language Editor: K. Brown) 